\title{
Jürgen Habermas: Religion, Cultural Diversity and Publicity
}

\author{
Paula Montero \\ Department of Anthropology, University of São Paulo, São Paulo, Brasil \\ Email: pmontero@usp.br
}

Received 24 May 2014; revised 21 June 2014; accepted 15 July 2014

Copyright (C) 2014 by author and Scientific Research Publishing Inc.

This work is licensed under the Creative Commons Attribution International License (CC BY). http://creativecommons.org/licenses/by/4.0/

(c) (i) Open Access

\begin{abstract}
The aim of this essay is to reflexively consider the particular way in which Jürgen Habermas faces some theoretical challenges that are particularly interesting to contemporary anthropological thought, i.e., the issue of cultural translation and the presence of religion in the public sphere.
\end{abstract}

\section{Keywords}

\section{Religion, Modernity, Public Sphere, Cultural Translation}

\section{Introduction}

Even if contemporary religious phenomena are undergoing profound changes, their study has been restricted to the traditional frontiers of disciplines, especially those of sociology and anthropology, which face difficulties in renewing their instruments of analysis and the way they formulate problems in this field because they have inherited this subject as a classical object of their own formation. This article intends to face the challenge of expanding these frontiers in order to rethink religion by activating different conceptual devices from approaches that do not have this field of study as one of their main foci.

In previous works, the author had tried to demonstrate how the Weberian paradigm of secularization ended up creating an epistemic obstacle to the understanding of processes hinting at the presence and visibility of religious phenomena in the public sphere (Montero, 2006). It has therefore been suggested that authors such as Jürgen Habermas would allow us to think of this issue without supposing that the emergence of the public sphere would be the result of the orientation of religious phenomena to the private world and that the permanence and even expansion of religious actors and discourses in this sphere would need to be represented, especially in societies like our own, as an obstacle to the consolidation of democratic processes. The purpose here is to provide a conceptual foundation to what was then presented merely as an insight and, especially, to develop the consequences of such an approach for the anthropology carried out in this field. Moreover, the reading of 
Habermas proposed in this essay, which is evidently partial and biased, understands that his model of critical theory establishes a dialogue with various of the issues that presently challenge the human sciences, especially the dilemma opposing, on one hand, the need to acknowledge cultural particularities and, on the other hand, the issue of how to translate diversities in order to build more universal consensuses (Nobre, 2008: pp. 19-20) ${ }^{1}$. By refracting the field of religious studies from the perspective of this dialogue, the anthropological approach gains momentum to produce a more encompassing diagnosis of the present, a project that has been abandoned by current post-modern anthropology, which has finally renounced the possibility of producing any social theory in the wake of its criticism of the classics (Marcus, 1991: p. 15)².

The work of J. Habermas is known to be very broad and to change its theoretical approach as it goes along the time. In the context of his work in 1962, the concept of publicity had to do with the analytical reconstruction of the historical process of social construction by means of the emergence of bourgeois institutions of publicity. According to Lavalle (2002), as the author became more distant from his genetic considerations of the emergence of the social, the concept of publicity was freed from its bourgeois particularities and came to designate an abstract principle of intermediation between the state and society. In this redefinition, the supposition of an empirical institutional support of publicity is abandoned in favor of the idea of the intangible articulation of "communicative flows," a necessary foundation for the processes of political legitimization materialized when public opinion gains publicity. In his work in 1981, "The theory of communicative action," the social structure of the public sphere is described on two levels - the systemic level and the life-world-accompanied by a differentiation of actions based on social rationality: instrumental actions aimed at reproducing the system (the market, institutionalized political power, the state or administrative power) and communicative actions aimed at understanding (peripheral networks of the public sphere) (Nobre \& Terra, 2008).

The intention of this article is to recover the particular way in which Habermas faces, based on his concepts of publicity, legitimacy, and communicative action, some challenges that are considered to be of particular interest to contemporary anthropological thought: the issue of cultural translation, or the irreducible character of differences, and the issue of the role of religion in the public sphere. In order to approach these issues, the dimension of the "life-world", the sphere of interactions in which communicative actions aim at appropriating what exists and at producing meanings that escape administrative control, will be privileged. On this level it may not be adequate to use the notion of public sphere as elaborated by Habermas in his work in 1962, which at the time supposed the support of proper political institutions and processes of argumentation (Habermas, 1999) ${ }^{4}$. However, there is the purpose of recovering the notion of "publicity" elaborated in the first phase of his work, not so much to recover its historical dimension, but to emphasize the permanence, in societies such as our own, of spaces of dialogical interaction connected to more or less peripheral institutional bases that are relatively autonomous regarding the state and the political and administrative institutions that model the life-world, and that contribute to form public opinion by supporting religious discourses ${ }^{5}$.

\section{The Cultural Translation of Difference as an Anthropological Issue}

In his 1981 work, The theory of communicative action, Habermas dedicated a long chapter to the definition of

\footnotetext{
${ }^{1}$ Marcos Nobre, editor of the book Curso livre de teoria crítica, suggests that the contributions of critical theory make it possible to understand specific phenomena from a perspective that is broader than that of specialists. Even though it is not possible to dispense with specialized knowledge, it is necessary, according to him, to seek to progressively foster dialogue between the disciplines in order to come to an accurate and plausible diagnosis of our time. And although the author of the present text is not in the field of studies in critical theory, Nobre's suggestion of facing the challenge of "finding new productive relations between the disciplines" serves as an inspiration to the present discussion.

${ }^{2}$ Generalization based on ethnographic practice is a classical issue. George Marcus observes that ethnography, as an instrument of description, has never properly dealt with more encompassing conceptual issues. The world of "larger events" is always, according to him, portrayed as external to smaller worlds and is not integrated into the analysis.

${ }^{3}$ In his work Between Facts and Norms: Contributions to a Discourse Theory of Law and Democracy, Habermas defines the life-world as a system of specialized actions and knowledge related to the school, religion, and the family, the function of which is to reproduce the life-world and to validate communicated knowledge.

${ }^{4}$ When the public sphere is generalized, that is, becomes detached from the physical spaces of simple interactions, communicative structures are, according to Habermas, compressed into contents and stances that are disconnected from the dense contexts of these interactions.

${ }^{5}$ The concept is used here in its more encompassing sense, as proposed by authors such as Benhabib (1996). By criticizing the Habermasian notion of "bourgeois public sphere" coined in the 1962 historical work, the author proposes that the volume of the public sphere be filled in by a diversified range of communicative processes elaborated in different micro fields. According to Sérgio Costa’s (Costa, 2002: p. 4) reading, Habermas revisits his arguments about the decline of the bourgeois public sphere in the 1990 revised edition of his book The Structural Transformation of the Public Sphere. In this work, Habermas reaffirms the importance of the public sphere as a realm in which collective opinion and will are constituted.
} 
the characteristics of mythical thought in order to demonstrate why, in its basic attitudes towards the world, this type of knowledge does not allow rationally oriented actions, that is, self-reflexive actions aimed at the discussion of rules pertaining to communication itself. Based on classical authors of anthropology, such as Lévy-Bruhl, E. Pritchard, Lévi-Strauss, and M. Godelier, the author argues that the analogical thinking that sustains this type of knowledge places things and people, objects and agents, communicative and teleological action, instrumental intervention and interpersonal relations on the same level. In this sense, the claims to validity that were differentiated in modern thought - that is, the shared observation that a state of things exists as something objective (the truth of the proposition), the presupposition that there is communicability of shared rules (the correction of the rule), and adequateness to the subjective world (sincerity of expression)—, form a single unit in mythical thought. Thus, different from the modern presuppositions of the understanding of the world, societies based on this type of thinking are not oriented towards dissent and discussion of rules.

By positing that rationality thus understood is not a universal phenomenon, Habermas revisits a classical issue of anthropology: the commensurability of civilizations, an issue that has been central to debate in social science and philosophy since the 1960s. Not all of the author's arguments in the debate will be recovered in this text, but for the purpose of rethinking the irreducible character of differences within modern societies, attention will be paid to three fundamental issues raised by the author in his trajectory. The first issue concerns the contextual and historical level: Habermas observes that interest in theoretical generalization and openness to criticism is a cognitive requirement that applies to traditional societies only when they are compelled to interact with other worldviews. The second issue refers to anthropological investigation itself: When anthropologists face a worldview that seems irrational to them (or that is not based on their own way of viewing the world), there is no other choice than trying to elucidate its meaning. For Habermas, however, this does not mean that it is necessary to suppose the existence of "alternative rationalities." Finally, in his theory of modernity/rationality, the author argues that modern thought may not be described only by the formal properties of scientific mentality-the utmost purpose of worldviews is not only to build a cognitive set of instruments on external reality, but also to produce understanding regarding the common social world as well as subjective experience. Thus, it would be necessary to include different aspects of the validity of propositions according to whether the discourse is theoretical, practical, aesthetic, therapeutic, etc., for worldviews are not only cognitive processes, but also work to make identities stable, even if they do it in a manner that is increasingly formal and open to revision in contemporary societies.

The issues privileged in this debate make it possible to outline a program of investigation to think of the issue of the communicability of differences and of how to come to consensus between the various modes of viewing the world within contemporary societies. As for the first observation above, it is necessary to point out that presently it is only possible for anthropologists to study "mythical" worldviews which are already in a somewhat long process of interaction with reflexive worldviews. Thus, the requirement of reflexivity and openness to revision must part of their propositions.

This leads to the second observation. By posing the issue as the elucidation of the meaning of a worldview perceived as different, anthropology has embraced the issue of how to translate the native's "point of view". Post-modern criticism has repositioned this issue in contemporary terms by reminding us that the suppression of the view from afar - a historical condition for the construction of differences as alterity — has forced ethnography to change its conventions in the description of differences. Marcus and Fischer (1986: p. 168) has called attention to the fact that, differently from what occurred in the $19^{\text {th }}$ century or in the 1920 s, the figure of the "primitive" is contemporarily no longer an attractive force. Even if

[...] the challenge to discover and represent cultural diversity is strong, doing so in terms of spatio-temporal cultural preserves of otherness seems outmoded. Rather, the strongest forms of difference are now defined within our own capitalist cultural realm [...]. The Samoan or Trobriand islander, juxtaposed to us, is no longer as convincing or believable a figure for an alternative way of being as he once was.

It would thus be necessary to abandon the trope of the "self-contained community" of the realistic ethnography of authors such as Malinowski: Instead of an exegesis of "cultures or cosmologies" that takes native categories out of their context and discourse in order to reinsert them into the analytical model of the ethnographer for them to become understandable through this "translation," the author suggests a dialogical appropriation of native and anthropological concepts. Transcultural understanding occurs, according to him, "by approximation and dialogue.” It would be the case for a mutual perfecting of understanding towards consensus (Marcus \& Fischer, 
1986: p. 29). In this process, the observer/observed relation would necessarily introduce reflexivity into other cultures: classical peoples would assimilate and appropriate the anthropological knowledge produced with reference to them.

In spite of the theoretical advance of this proposition, by taking into account that it is not possible to represent "another" culture without supposing that reflexivity has already been introduced into the very process of representation, it still places the process of construction of meaning in the anthropologist's relation to his subject, and thus produces confusion between the sphere of the self-understanding of subjects and the sphere of the subject of anthropology. The Habermasian approach allows us to suggest an ethnography of the very processes of negotiation of meaning. It seems that ethnographic works, both in the phenomenological approach-which is concerned about how natives "view the world"-and in the hermeneutic approach—which poses the question of how natives "decipher their texts"-, remain tied to the postulate of "the native's point of view," which poses the need for a reconstruction that is "not contaminated" by the reflexivity of the other's significations or for a model that is capable of objectifying the other as something that is previous to the relationship of knowledge that apprehends the other. But it is no longer plausible to put the process of interaction in epoche so as to produce an irreducible model of alterity; contrarily, it is more analytically productive to focus on the issue of how different worldviews communicate and dispute the meanings they attribute to the social and subjective world. An ethnography of the processes of reflexivity and dispute concerning differences would make it possible to understand the temporary consensuses that give a certain stability to particular distinctions between $u$ s and them that are produced in given contexts.

The last observation-i.e., that for Habermas rationality aimed at understanding encompasses propositions of practical, aesthetic, therapeutic, etc. character — suggests that religious language may be included in his discursive model of rationalization on two levels. This language, which is embedded in the modes of expression that characterize the life-world, is also, to a great extent, aimed at producing understanding concerning the common social world and the subjective experience of differences and identities. Thus, although Habermas has not explored this possibility, his insight provides a foundation for an approach of the classical issue of the production of meaning in linguistic interactions. The Habermasian concept of "communicative action" makes it possible to displace the issue of the understanding of "the native's point of view" from the sphere of the internal meanings of culture, which defends consensus as an ethical disposition of the anthropologist, that is to say, from the sphere of translation as the "authentic" representation of a far-away experience, to the sphere of discursive interactions that produce the differences between "us" and "them." It is thus a matter of analyzing the play of reflexivity and the manner in which each actor exposes his/her own images of the world by means of discourse as opposed to the images of others, so as to play the game of the claims to validity of the interpretations of the world made visible and thinkable by discourses.

By assuming Peter Winch's interpretation of Wittgenstein's theory of language, Habermas states that the comparison between images of the world in interactions should take into consideration not only knowledge of the world and control over nature, but also the potential for providing a foundation for meaning concerning the order of the world. Discursive interactions are thus not related to the abstract comparison between values in order to find their equivalence and/or translation from one repertoire into another. Contrarily, the idea is to understand how, by means of discursive actions, consensus on rules of action with prescriptive validity is produced. This displacement makes it possible to overcome the theoretical problem, always posed in ethnographic description, of how to attain the last source of distinction between cultures, an operation without which it would seem impossible to understand them. The question imposed by contemporary ethnographic conditions which the Habermasian theory helps to formulate anew concerns the linguistic procedures that lead to the production of agreement on what differences are and what they mean. This way of giving order to the issue of differences on the level of language reinvigorates anthropological imagination concerning the issue of cultural specificities in terms of their dispute for visibility in the public sphere within our own society.

\section{Religion, Publicity, and Communicative Action}

The present necessity of co-existence of cultural differences have made one of the characteristics of modern society that stands out the most even more pressing: the imposition of the simultaneous existence of a plurality of concepts of the world and forms of life in the same political sphere (Nobre, 2008: p. 16). Until very recently, the Catholic Church was able to produce, in societies of the European historical matrix, the symbolic and institutional connections that mediated these various ethnicities. According to Nobre (2008), in the political theory 
elaborated by Habermas since Between Facts and Norms, law plays this role today: It is a mediating institution capable of transforming the communicative power that is present in society's foundation into administrative power. Although law has eventually taken up the mediating function that was for centuries a prerogative of the Christian religion in the West, it seems that religions are still an important part of the symbolic dynamics which, in societies such as our own, modulate lived experiences and processes of socialization. However, the concept of publicity will not be focused on so that we may analyze processes in which religion serves as a mediator between society and the state; it will be resorted to analytically in order to understand the way in which the present and virtual meanings of differences that circulate as possibilities in the horizon of the life-world are established, even if temporarily, through the mediation of religious categories in a configuration of identities gaining public visibility and expression.

In order to understand the role of religion in the Habermasian model more clearly, an attempt will be made at explaining in detail the distinctions and relations, sometimes little explored in his work, between the notions of publicity, public sphere, and the life-world. Costa (1977: p. 35) suggests that the forces of communicative interactions aimed at understanding are not immediately transferred to the political and institutional level. As for interactions in the life-world, not all of them become public. The idea of "institutions of publicity" found in Habermas' 1962 work, which was subsequently dissipated by its metamorphosis into a more abstract notion of publicity as communicative flows, seems to still be useful to understand the dynamics of practices of publicity from the perspective of anthropology ${ }^{6}$. In the space provided by non-state institutions, peripheral institutions such as churches and other religious associations, both in their public and private dimensions, mold in their own terms some of the claims to validity arising from interactions in the life-world concerning the stabilization of identities.

Let us now investigate whether Habermas' reflection on religious phenomena allows for this type of anthropological appropriation.

Apart from Habermas' comprehensive theoretical effort in 1981, in which he criticizes the Weberian concept of rationality as resulting from the process of decentering of the world, the subject of religion was not granted any specific treatment by the author until 2006, when he published the article "Religion and the public sphere" in the European Journal of Philosophy.

Habermas started to think of the issue of religion more explicitly in the context of the political challenge of religious fundamentalism and the ethnic conflicts in the Europe of the 1990s. This conjuncture causes the author to revisit his debate with the Weberian model, which associates modernization to the secularization of the world. The author is particularly surprised by the political revitalization of religion in the United States, where the dynamism of modernization has been successful. Thus, he suggests that the immediate association Weber helped to build between religion and traditionalism must be reviewed.

In his 2006 work, Habermas acknowledges that, differently from what the Weberian theory of secularization had postulated, the history of modernization has not always coincided with the history of secularization. In the United States, the introduction of religious freedom did not mean a victory for secularity but rather, the introduction of the idea of tolerance concerning religious minorities, for there was historically the need to guarantee colonists fleeing from religious wars in Europe the freedom to go on practicing their own religions (Habermas, 2006: p. 33).

Moreover, the author also acknowledges that churches and religious communities still play important roles in the stabilization of a secular public culture today, and some are even requested by the state to do so (Habermas, 2006: p. 6). Thus, it is not possible to defend that religious phenomena should be understood as relics from the past and religious freedom should be considered a cultural version of the conservation of endangered species. From such a perspective, religion would not have any intrinsic reason to exist and would not be capable of resisting the pressure for modernization.

How to solve then the aporia of the Weberian model, in which religion would require its followers to "sacrifice their intelligence," preventing them from following the procedures of democratic debate in res publica?

Habermas' position in this dispute seems very interesting. He defends that religions may have cognitive con-

\footnotetext{
${ }^{6}$ According to Lavalle (2002: p. 69), the idea of publicity in Habermas evolved from its genetic meaning of the historical construction of the material and moral autonomy of the bourgeoisie to a more abstract concept: the status of what is public. Bourgeois publicity as a historical phenomenon would have enabled the constitution of the notion of public sphere, a space for the formation of consensus expressed in public opinion. According to Lavalle, Habermas has more recently redefined the concept of publicity in terms of spontaneous communicative flows thus abandoning the need for institutional support.
} 
tributions for the political sphere (Habermas, 2006: p. 15). However, they present their arguments in the context of a post-secular and post-metaphysical society that does not postulate that reason is finite. The epistemological stance of Weberian sociology and the philosophy of consciousness are thus confronted. And his theory of the communicative action is fundamental in this sense.

As had already been the case in Habermas' reading of Weber, the author acknowledges the historical importance of religious doctrines in the genealogy of our idea of reason (Habermas, 1984). Moreover, he rejects a limited, overly scientific conception of reason that excludes and looks down on all categories and affirmations that may not be reduced to controlled observation, nomological positions or causal explanations. Thus, the author expands his concept of reason in order to incorporate moral, legal, and religious judgments (Habermas, 2006: p. 16). His contribution to the study of phenomena of interest for the anthropology of religion seems to lie in this opening. In his multidimensional concept of reason, the latter dos not occupy a fixed position in its reference to the objective world. Moral and religious judgments dispute their conception of the world with other judgments. With accurate anthropological sensitiveness, Habermas recognizes that all knowledge depends on how men interpret themselves and their position regarding nature. But contrarily to anthropological thought, which tried to expand the concept of reason by making it relative, Habermas understands that reason may not be considered in this way because it does not concern contents or forms of knowledge, but forms of procedure. The procedures of rationality are, according to the author, of discursive nature. The performative attitude of participants in any interaction mediated by language is to be pointed out: Linguistic performance is an instrument for the emergence of consensus concerning the rules and conventions that define the unit and meaning of the world. They are, therefore, permanently subject to controversy. "Communicative reason" is, therefore, dialogical not in the sense of the subject/object relation as it is understood by post-modern anthropology, but because speakers have claims to validity concerning existing things, interpersonal bonds, and experiences. And these claims will only be accepted if they are capable of producing consensus regarding their own validity.

Thus, although the author takes Weberian success-oriented instrumental reason into consideration, the focus of his analysis lies on interaction-oriented and understanding-oriented reason (Araújo, 1996: p. 127). In order to formulate this dimension of action called "communicative action," the author resorts to Austin's distinction between speech acts: perlocutionary acts—which affect the listener (in order to frighten, persuade him) and thus depend fundamentally on the situation of enunciation to cause something in the world; illocutionary actswhich carry out the action named by the verb (the speaker accomplishes something by saying it, and what is essential is the meaning of the enunciation); locutionary acts—-the speaker says something.

For Habermas, the speech acts of actors have illocutionary purposes in communicative action, although, according to Araújo, he acknowledges the presence of perlocutionary strategies in linguistically mediated interactions (Araújo, 1996: p. 127). George Herbert Mead provides Habermas with a theory of action based on an interaction model that was subsequently developed by the author in terms of communication. Moreover, by stressing the symbolic character of social actions that are no longer taken for a mere mechanical translation of rules, but understood as open and subject to continuous recognition, Mead also suggests a way to overcome a monological perspective on the theory of action. In Mead, Habermas finds the roots for a pre-linguistic communicative action connected to the world of observable objects and to the affirmation of identities (Araújo, 1996: p. 185).

Authors such as Pierre Bourdieu have also found inspiration in Mead and symbolic interactionism in order to integrate a theory of symbols and a theory of action conceived of in a less mechanic way, and not as a by-product of structure. However, although Bourdieu also takes language into account to think of the logic of practices, he does so in the framework of the Durkheimian reading of "representation," which privileges categories of knowledge and their logical functions. The social forces of representation are, for Bourdieu, a dispute for the classification of the social world, a struggle for the monopoly of making seen, and legitimately acknowledging, the existence of social divisions. In this sense, for him, representation builds the world it represents to a great extent.

As for Bourdieu, for whom the symbolic world makes consensus on the social world possible because logical and moral integration are associated, Durkheim's theory of solidarity offers Habermas a social theory that relates social integration and system integration. Durkheim considers the concept of "obligation" to be one of the characteristics of moral rule (Araújo, 1996: p. 149). But sanction is only one aspect of the acknowledgement of rule; it is necessary to also take into account the desire to comply with it. These two characteristics of the moral fact—desire and duty—have led Durkheim to propose an analogy between the sphere of morality and that of the sacred. Thus, Durkheimian anthropology offers Habermas a model to integrate pre-linguistic ritual actions into 
his analysis: They express a normative consensus that is continuously updated. However, the normative consensus guaranteed by rite and mediated by symbol is the "archaic core" of collective solidarity. In modern contexts of action, religious symbols are no longer capable of expressing collectivity on their own. The normative consensus that used to be guaranteed by rite, based on religious symbols and interpreted by means of the "semantics of the sacred," is dissolved and gives way to the "verbalization of the sacred", that is, to structures of action aimed at mutual understanding. Thus, the authority of the sacred is gradually replaced by that of consensus (Araújo, 1996: pp. 157-158).

Based on this idea of "verbalization of the sacred," Habermas makes it possible to move the symbolic issue from the field of representation to the field of action as argumentation: Understanding the other does not depend, as in the tradition of understanding of Dilthey and Weber, on the possibility of (re)presenting the thoughts and feelings of those whose conduct or thought should be understood, nor on taking up the point of view of the actors (Giddens, 1995), but on establishing a dialogue with them. Understanding is thus not considered as a particular method of investigation, in the way interpretive anthropology absorbed the phenomenological supposition of the possibility of (re)experiencing the exotic, but the way in which life itself is constituted. On this non-systemic level, action is developed in the realm of the "life-world," of lived experience, whose symbolic function is oriented towards consensus. The "lived world" is the horizon in relation to which communicative processes and interaction occur: It delimitates the situation of action, but remains inaccessible to thematization ${ }^{8}$.

Although the notion of "lived world" is still little systematized in the work of Habermas, it was developed based on the phenomenological tradition of Edmund Husserl and Alfred Schütz ${ }^{9}$. For Schütz, it constitutes the sphere of daily experience and work, in which the use of subjective and situational "practical reason" prevails, for it is aimed more at usefulness than at truth (Wagner, 1983: p. 291). In this sense, "life-world" in Schütz may be understood as a context of convictions which are not explicitly formulated and serve as a background for social interaction. Habermas relies on this Schützian notion and emphasizes its function in intercommunication: This pre-reflexive context offers a reserve of non-objectified convictions that are nonetheless linguistically structured, and actors resort to it to sustain their interpretations. It is based on this implicit and non-problematic knowledge that, according to Habermas, speakers and listeners may reciprocally intend that their enunciations coincide with the (objective, social, and subjective) world, criticize, and lay the foundations for their claims to validity, solve their divergences, and come to an agreement. However, in view of its own characteristics pertaining to the classical phenomenological tradition — that is, its immediacy, its totalizing force, and its holism-, it is not possible to produce an external and objectifying view on it (Araújo, 1996: p. 161).

By taking up the notion of "lived world" from Schützian sociology, Habermas seems to frequently associate it to the concept of "culture as tradition" that is characteristic of phenomenological schools. However, attentive as he is to the essentialism that is inherent to this stance, the author seeks to correct the culturalist reduction of this concept by suggesting that traditions are only one of the three components of the experienced world. In addition to culture, there are also institutions, which guarantee solidarity, and the competences of personality. These three levels of the "life-world" may not, therefore, be treated as social facts; contrarily, they are formulated in terms of communicative interaction:

[...] I call culture the store of knowledge from which those engaged in communicative action draw interpretations susceptible of consensus as they come to an understanding about something in the world. I call society the legitimate orders from which those engaged in communicative action gather solidarity, based on belonging to groups, as they enter into interpersonal relationships with one another. Personality serves as a term of art for acquired competences that render a subject capable of speech and action and hence able to

\footnotetext{
${ }^{7}$ For Habermas, the history of societies is oriented towards the growing demand for linguistically organized legitimization. Archaic societies interpreted themselves through myth and established their normative validity by themselves. Traditional societies interpreted themselves by means of theological narrative, and their normative validity depends on laws guaranteed by the sacred power of a political chief. In modern societies, argumentation replaces doxa: "Culture has the task of justifying why the existing political order deserves to be recognized." (See: Habermas, 1984).

${ }^{8}$ Habermas distinguishes two opposed spheres in permanent tension in complex societies: that of the life-world and that of the system. The more complex social systems are, the more peripheral life-worlds become. However, every increase in complexification on the first level will only gain force if followed by an equivalent process on the second level (Araújo, 1996: p. 165).

${ }^{9}$ Schütz takes up the term from the work of Husserl. In 1940 he declared that phenomenology is "the philosophy of the life-world.” According to Helmut R. Wagner's reading of his work, Schütz dedicated a considerable part of his interpretive effort to the exploration of the structures of cognition and experience of the life-world. His objective was to reinterpret the world of work not from the perspective of institutional arrangements or the economic system, but from the perspective of human intention, cognition, and subjective effort towards cooperation (Wagner, 1983: pp. 289-290).
} 
participate in processes of understanding in a given context and to maintain his own identity in the shifting contexts of interaction (Habermas, 1984: p. 344).

The notions of store, legitimacy, and competence associate these three levels on a procedural and non-structural level. It is in the very dynamics of communicative interactions that what may be accepted as knowledge, what is recognized as legitimate, and those who may speak gain visibility and are materialized as "facts."

If, as was proposed by Weber, the historical process of rationalization of the world has produced the disjunction of spheres ${ }^{10}$, for Habermas, language plays the same role as myth used to in the production of consensus today. Thus, contrary to what Weber intended with his notion of empathy, understanding action from the perspective proposed by Habermas would be related to the investigator's capacity of describing actions in linguistic terms, that is, the way in which common language codes the perception of the world and its rules.

Although his model of the social evolution of modern societies supposes a progressive distance between mythical narratives and the level of the sphere of validity, in his 2006 article, Habermas recognizes that religion still provides an important cognitive basis for the world of daily life. Thus, as part of the experienced world, he proposes that it should be analyzed as a component of the common language that is mobilized in contexts of interaction. It is certain that if these contexts aim at communicability, religious narratives must also necessarily produce and base themselves on shared procedures. According to Habermas, reflexivity is one of the most important characteristics of this type of interaction. Thus, all religious certainties are, as any other, more and more exposed to the need to "view the own faith from the outside," that is, to be capable of objectifying it and relating it to other points of view.

It is here that the concept of life-world meets the concept of publicity in Habermas. The category of publicity, which is central to Habermasian work, has allowed the author to articulate the Weberian notion of rationalization with the political notion of legitimization. In the context of his 1962 work, the constitution of the public sphere was historically associated both with the contraposition to absolutism and the traditional authority, and to the restriction of the upward mobility of subordinated classes. However, abandoning the idea of institutions of publicity, such as saloons, museums, newspapers, and churches for the idea of flow does away with the basis for an empirical investigation oriented towards the understanding of why only some meanings make sense. From the point of view of anthropological investigation, it is not enough to state that religious discourses are still capable of producing meaning: It is necessary to explain why some religious categories are more successful than others in establishing these meanings, why some religious institutions are more capable than others of producing veritable propositions in this respect. If a wide and varied set of meanings is available in a given moment, not all of them remain because not all of them are perceived as legitimate. Actually, the processes of legitimization that occur on the level of linguistic mediations depend, as has been previously mentioned, on publicity to establish consensus regarding the meanings of things and intentions, even if temporarily. The concept of public sphere would thus have a more profitable use if taken as the locus where cultural controversies and negotiations between various publics occur (Geoff, 1996: p. 306).

Because the principle of publicity is considered a condition for democracy, the public sphere is constituted as an abstract and virtual space of public criticism for Habermas. It is in this sense that religions are also part of the process. Habermas recognizes that religions may present their arguments in public debate and gain legitimate adherence to their propositions. For Habermas, it is not a problem if common people express their convictions in religious language or arguments. From the perspective of the political system, what matters for Habermas are the affirmations and issues that can motivate decisions cognitively and gain visibility in the impersonal flow of public communication (Habermas, 2006: pp. 6-13).

Thus, the author acknowledges that religion provides daily life with a cognitive basis, and that many individual decisions are made based on it. In his 2006 article, Habermas makes his previous positions more flexible and accepts that, for functional reasons, the polyphony of public voices may not be reduced. For him, the conflict between doctrines and cultures that dispute the explanation of man's position in the world may not be solved on the normative or philosophical level. If epistemic attitudes express a particular way of viewing the world, it is only on the level of law that the reciprocity of expectations may be produced. This emphasis in procedures partly mitigates the dissatisfaction of his critics with what was perceived as an idealization of rational discourse in the formation of the public sphere (Eley, 1996: p. 312). Although the notion of public sphere-which supposes the legitimate production of the authority of discourse-may in fact be criticized for the supposition of homo-

\footnotetext{
${ }^{10}$ Revisiting the Weberian idea of secularization as the separation between the spheres of economy, politics, religion, philosophy, aesthetics, and eroticism (Weber, 1946), Habermas proposes a separation between life-world and system on the first level and, within it, the disjunction between culture, society, and personality, on the one hand, and stratification, state organization, and law, on the other hand.
} 
geneity and univocity that is inherent to it, the introduction of the subject of religion and the acceptance of religious language in the debate make this dispute more important than the quality of discourse regarding the validity of procedures.

If the principle of publicity is the utmost rule of the game in the production of legitimacy, as suggested by Lavalle (2002: p. 78), there is, then, a limit to Habermasian theory in the exercise of polyphonic reasons. Between the "savage life" of the public sphere and the formal procedures of political bodies there is, for the author, an institutional demarcation, "a filter that allows only secular contributions from the Babel of voices to pass through" (Habermas, 2006: p. 9). Nevertheless, the force of religious discourses will continue to exercise its right as a persuasive language in the public sphere while other more convincing languages are not conventionalized to express a certain type of experience. What is required is the exercise of a type of reflexivity that relates faith to other points of view-an epistemic attitude that is inherent to communicative action and is based on the independence of one religion from the others, and from religions to secular thinking, the reasons of which prevail in the properly political arena (Habermas, 2006: p. 14). Thus, although Habermas excludes communicative action from the field of politics and confines the latter to the systemic world governed by instrumental action, it is possible to make the very concept of politics more encompassing in order to include the symbolic disputes governed by discourses by retaining the "principle of visibility" as a key notion. From the perspective of political relations conceived of in this more encompassing way, what is possible to retain as a significant advance of the Habermasian model is its articulation of what is cognitive and motivational in the religious world-already known by the tradition of anthropological studies — and the discursive processes of production of visibility in the impersonal flow of communication. Because they are intangible, it is necessary for anthropological observation to have the means to describe these evanescent and unsystematic moments in which "the formation of opinion emerges from the life-world and comes to public light” (Lavalle, 2002: p. 80).

\section{Conclusion}

The re-reading of the notion of public sphere elaborated in his work in 1962 makes it possible to constitute as new objects of anthropological analysis, not only the objectification of pre-constructed religious identities, cultures, and beliefs that defend their (natural) rights in the political arena, but also the communicative flows from the life-world and the way they discursively establish identities, traditions, and beliefs. Cultural controversies and negotiations between various publics concerning the validity of certain propositions occur and become visible in the public sphere. By focusing on processes of reflexivity, anthropology may contribute to shedding new light on the modalities of consent from which operation every political activity derives.

\section{References}

Araújo, L. B. L. (1996). Religião e Modernidade em Habermas. São Paulo: Loyola.

Benhabib, S. (1996). Models of Public Space: Hannah Arendt. The Liberal Tradition and Jünger Habermas. In C. Calhoun (Org.), Habermas and the Public Sphere. MA: Massachusets Institute of Technology.

Costa, S. (1977). Contextos da construção da Esfera Pública no Brasil. Novos Estudos do Cebrap. N. 47.

Costa, S. (2002). As cores de Ercília. Esfera Pública, democracia e configurações pós-nacionais. Minas Gerais: UFMG.

Eley, G. (1996). Nations, Publics, and Political Cultures: Placing Habermas in the Nineteenth Century. In C. Calhoun (Org.), Habermas and the Public Sphere. MA: Massachusets Institute of Technology.

Giddens, A. (1995). Politics, Sociology and Social Theory. Cambridge: Polity.

Habermas, J. (1984). The Theory of Communicative Action. Boston: Beacon Press.

Habermas, J. (2006). Religion and the Public Sphere. European Journal of Philosophy, 14, 1-25. http://dx.doi.org/10.1111/j.1468-0378.2006.00241.x

Lavalle, A. G. (2002). Jünger Habermas e a virtualização da publicidade. Margem, No. 16.

Marcus, G. (1991). Problemas de la antropologia contemporânea em el mundo moderno. In Retóricas de la Antropologia. Madrid: Jucri.

Marcus, G., \& Fischer, M. (1986). Anthropology as Cultural Critique. An Experimental Moment in the History of Social Sciences. Chicago, IL: University of Chicago Press.

Montero, P. (2006). Religião, pluralismo e esfera pública no Brasil. Novos Estudos-Cebrap, No. 74. http://dx.doi.org/10.1590/S0101-33002006000100004 
Nobre, M. (2008). Curso Livre de Teoria Crítica. São Paulo: Papirus.

Nobre, M., \& Terra, R. (2008). Direito e Democracia. Um guia de leitura de Habermas. São Paulo: Malheiros.

Wagner, H. R. (1983). Alfred Schütz. An Intellectual Biography. Chicago, IL: University of Chicago Press.

Weber, M. (1946). The Social Psychology of the World Religions. In From Max Weber: Essays in Sociology. New York: Oxford University Press. 
Scientific Research Publishing (SCIRP) is one of the largest Open Access journal publishers. It is currently publishing more than 200 open access, online, peer-reviewed journals covering a wide range of academic disciplines. SCIRP serves the worldwide academic communities and contributes to the progress and application of science with its publication.

Other selected journals from SCIRP are listed as below. Submit your manuscript to us via either submit@scirp.org or Online Submission Portal.
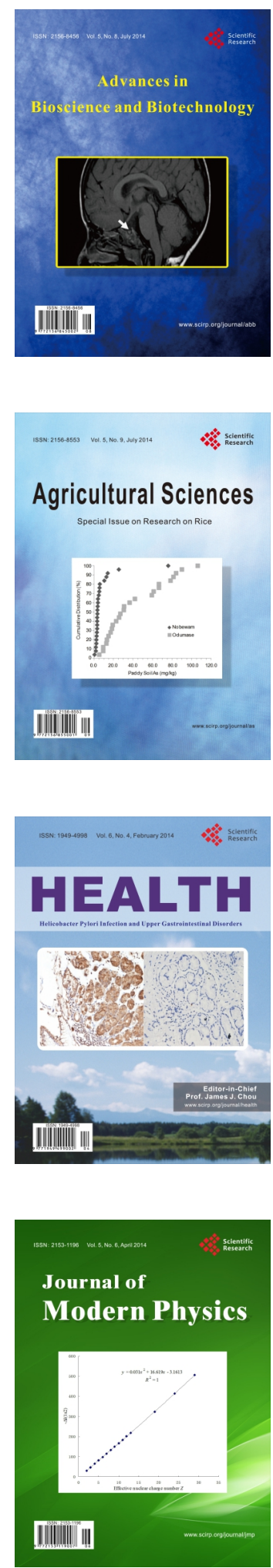
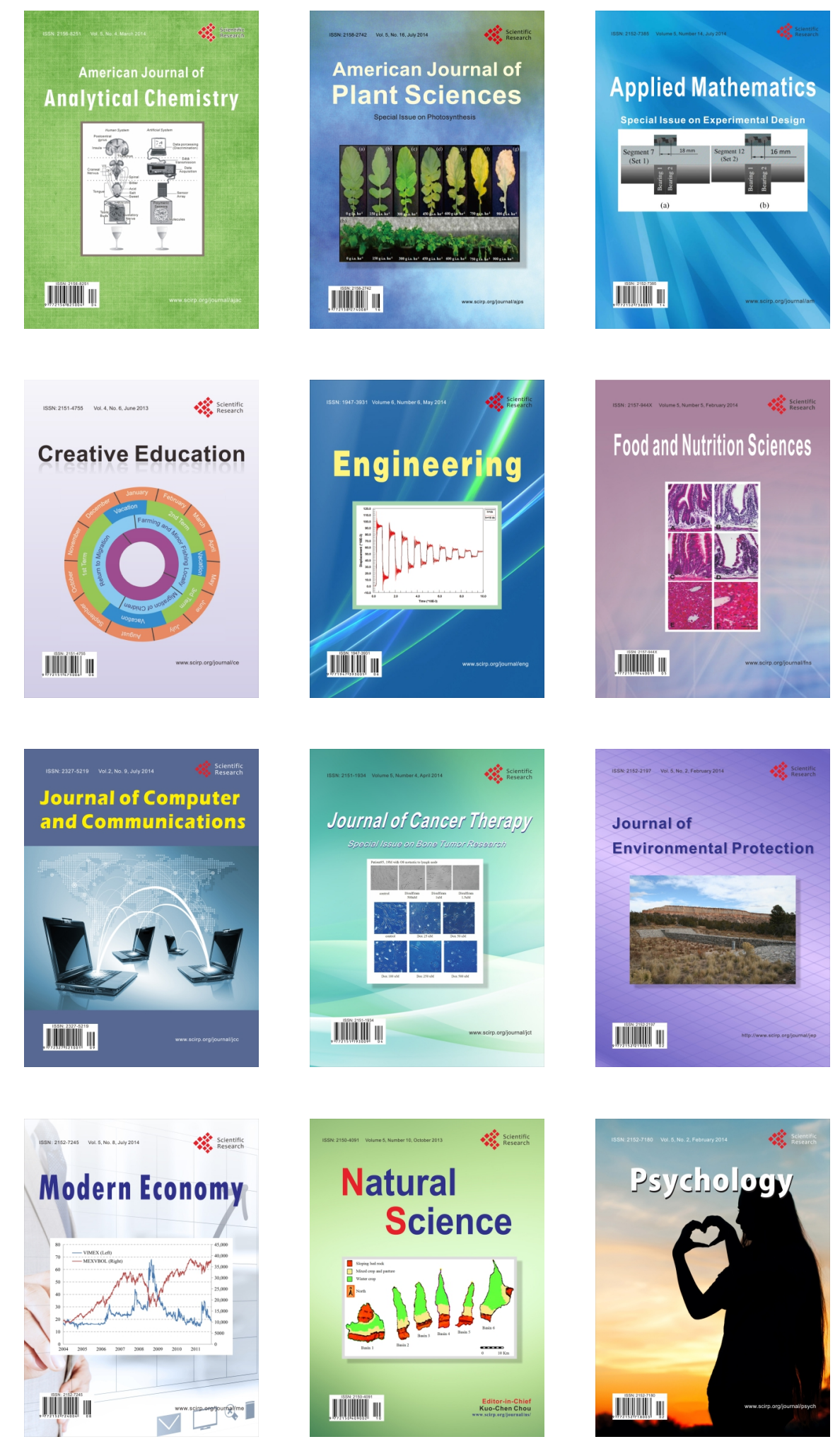